Original Research Paper

\title{
Gene Expression of FADS2 mRNA Linked to Intelligence in Exclusively Breast Milk Fed Preterms
}

\author{
${ }^{1}$ Naglaa F. Alhusseini, ${ }^{1}$ Amal Idris Ali, ${ }^{2}$ Azza M.A. Abul-Fadl, ${ }^{2}$ Amira A. Abu-Zied and ${ }^{3}$ Sheref M. El-Taher \\ ${ }^{I}$ Department of Medical Biochemistry, Faculty of Medicine, Benha University, Egypt \\ ${ }^{2}$ Department of Pediatrics, Faculty of Medicine, Benha University, Egypt \\ ${ }^{3}$ Department of Community Medicine, Faculty of Medicine, Benha University, Egypt
}

Article history

Received:20-08-2014

Revised: 30-08-2014

Accepted: 25-11-2014

Corresponding Author:

Naglaa F. Alhusseini,

Department of Medical

Biochemistry, Faculty of

Medicine, Benha University,

Egypt

Email: nagla.alhusseini@fmed.bu.edu.eg

\begin{abstract}
Breastfeeding is important for brain development and was shown by many studies to result in higher scores Intelligent Quotient (IQ). However, the exact mechanism whereby Breastfeeding influences cognitive development remains unclear. This study aimed to study the expression of genetic code FADS2 linked to the cognitive function in relation to the mode of feeding. The study comprised 30 preterm infants of 32 to 34 weeks gestation age including 15 exclusively breastfed and 15 fed on Infant Milk Formula (IMF) selected from the Neonatal Intensive Care Unit (NICU) in Talkha Central Hospital in Dakahlia Governorate Egypt. Blood samples were drawn at birth and at 12 weeks of life and FADS2 mRNA gene expression-was measured using real time PCR at birth and at 12 weeks of life. Blood indices were measured at 12 weeks. FADS2 mRNA gene expression demonstrated a significant increase from birth to 3 months, with 109 folds rise in breast fed group compared to five folds rise in the artificially fed group at $(\mathrm{p}<0.001)$. Breast milk influences gene expression. The higher FADS2 expression observed in the breastfed group can be used to predict higher IQ scores in the breastfed preterm. The mammary gland could be an organ that stipulates and regulates genetic expression in the newborn.
\end{abstract}

Keywords: FADS2-Breast Milk, Cognitive Function, Intelligent Quotient, Preterm, Gene Expression

\section{Introduction}

Breast milk provides optimal nutrition for a growing infant, with compositional changes that are adapted to the changing needs of the infant. Human milk contains adequate minerals and nutrients for the first six months of life (Butte et al., 2002). Children's intellectual development has been shown to be influenced by both genetic inheritance and environmental experiences. Breastfeeding is one of the earliest postnatal experiences and is important for brain development. Breastfed children especially when preterm were shown to attain higher Intelligent Quotients (IQ) scores than children fed on other milks. The higher IQ linked with breastfeeding and intelligence is linked to the high concentration of long chain polyunsaturated fatty acids as Docosahexaenoic Acid (D.H.A) and Arachidonic Acid (A.A). Also it contains cholesterol, amino acids as taurine and also lactose which is broken in the body to glucose and galactose, the latter is important for the formation of galactolipids for the myelination process in the nervous system and the former is important source of energy for the brain. All are important nutrients which play an essential role in brain and central system tissue growth and development early in life (Mortensen et al., 2002; Caspi et al., 2007; Walfisch et al., 2013).

Xie and Innis (2008) have provided evidence that genetic variation in FADS1 and FADS2 influence maternal plasma and erythrocyte phospholipids levels of (n-6) and (n-3) fatty acids during pregnancy and levels of saturated, monounsaturated, (n-6) and (n-3) in breast milk during lactation. Other studies have shown an association between the IQ and the genetic variant in FADS2, a gene involved in the genetic control of fatty acid pathway (Dauncey, 2009; Morales et al., 2011). The relationship between breastfeeding and this latter gene on the cognitive function of children is not fully verified. Hence, the aim of this study is to compare the FADS2 gene expression in preterm exposed to mother's milk in the early months of life with those exposed to infant milk formula. 


\section{Subjects and Methods}

This is a cross sectional study including 30 neonates whose age range was between $32-34$ weeks, attending the NICU of Talkha Central Hospital where they were followed up during the period of the study. They were divided into two groups: Group I: Included 15 preterm babies fed exclusive breastfeeding and group II: Included 15 preterm babies fed on artificial formula. Ethical considerations included consent from the hospital and from parents with explanation of the procedure and its out come to the family.

Anthropometric assessment included measurements of weight (wt) for age Length (L) for age and Head Circumference (HC) for age. Blood samples were drawn at birth and at 3 months for all babies. Laboratory investigations included full blood picture for hemoglobin and blood indices were done in TalKha Hospital Lab and another sample was sent to the Molecular Biology and Biotechnology Unit in Benha Faculty of Medicine for measuring FADS2 mRNA gene expression for the all groups at birth and then after 3 months. Complete blood count $\mathrm{CBC}$ was one only at age of 3 month.

\section{Sample Collection}

Two $\mathrm{ml}$ of anti-cubital venous blood were collected from each case and immediately put in a vaccutainer tube containing EDTA, Each sample was mixed and divided into two eppendorf tubes, one tube sent for $\mathrm{CBC}$ and the second stored at $-80^{\circ} \mathrm{C}$ for further processing in gene expression technique.

\section{Total RNA Extraction}

Total RNA was extracted using Gene JETTM RNA Purification kit, (Fermentas, EU) following the manufacturer instructions and the standard protocol. 40 $\mu \mathrm{L}$ of the eluted RNA was collected immediately, placed in ice or stored at $-20^{\circ} \mathrm{C}$ for further processing.

\section{Spectrophotometric Quantification of RNA}

To ensure significance, A260 readings should be greater than 0.15 . An absorbance of one unit at 260 $\mathrm{nm}$ corresponds to $44 \mu \mathrm{g}$ of RNA mL-1. The ratio between the absorbance values at 260 and $280 \mathrm{~nm}$ gives an estimate of RNA purity (Wilfinger et al., 1997). A260 and A280 were taken by Nanodrop Spectrophotometer 2000c USA.

Relative Quantitation of mRNA of the Respective Genes by Real Time PCR Using SYBR GREEN

In this study, the target gene sequences are the catalytic subunit of FADS2 gene and the calibrator sample is healthy control. A singleplex reaction is using, where a single primer pair is present in a well. In addition, we used One-Step RT-PCR using Quanti-
Tect ${ }^{\circledR}$ SYBR $®$ Green RT-PCR master mix kit (Qiagen. GmbH). In ABI 7900HT Fast Real Time PCR system (Applied Biosystem, USA) the prepared reaction components were done in 96 well PCR plate MicroAmp® 96 Well Optical Reaction Plate with Barcode, code 128), using real time cycler conditions of $48^{\circ} \mathrm{C}$ for $30 \mathrm{~min}$, (Reverse transcription), $95^{\circ} \mathrm{C}, 15$ min, (Initial denaturation) followed by 40 cycles of $94^{\circ} \mathrm{C}, 30 \mathrm{sec}, 48^{\circ} \mathrm{C}, 1 \mathrm{~min}$ and $72^{\circ} \mathrm{C}, 1 \mathrm{~min}$ for Denaturation, Annealing, Extension steps respectively. Primer sequence $\left(5^{\prime}-3^{\prime}\right)$ of hTERT was 5'- TGC AAC GTG GAG CAG TCC TTC T -3' (Forward) and 5'GGC ACA CATAGA GAC TTC ACC AGC -3' (Reverse). Primer sequence of glyceraldehyde phosphate dehydrogenase (GAPDH) as internal control (housekeeping gene) was 5'-TGA TGA CAT CAA GAA GGT GGT GAA G-3'(Forward) and 5'-TCC TTG GAG GCC ATG TGG GCC AT-3' (Reverse). The PCR primers were synthesized by (Operon, inc. Huntsville, Alabama Germany. According to the RQ manager program 1.2 ABI SDS software (ABI 7900HT), the relative endogenous quantities of the FADS2 Gene are normalized Against, the relative Quantities of the control (GAPDH) gene fold expression changes are calculated using the equation $2^{-\Delta \Delta C T}$ (Livak and Schmittgen, 2001).

\section{Statistical Analysis}

The statistical analysis was done by using Statistical Package for Social Science (SPSS, program) version 16. To test the normality of data distribution K-S (Kolmogorov-Smirnov) test was done. The description of the data done in form of mean (+/-) SD for quantitative data. The analysis of the data was done to test statistical significant difference between groups using student $t$-test to compare between two groups. $p$ value $p>0.05$ was considered insignificant while $p<0.05$ was considered significant.

\section{Results}

Our results revealed that there was no statistical significant difference in the mean age of mothers/year between breastfed group and artificially fed group $(26.6 \pm 6.1)$ and $(25.9 \pm 9.3)$ respectively $(p>0.05)$. As regard education of the mother there was no statistical significant difference in breastfed group when compared to the artificially fed group indicating that the two groups were a homogenous group with similar background from Dakahliya governorate. Anthropometric measurements of our studied groups showed a significant increase in the mean value of weight in breastfed group when compared to artificially fed group $(\mathrm{p}<0.05)$, but no statistically significant 
differences as regard length and head circumference $(\mathrm{p}>0.05)$ Table 1 and 2 .

There are statistically increases in RBCs, MCV MCH and WBCs and HB mean values in breastfed group when compared to artificially fed group but these increases not reach to the significant value $(\mathrm{p}>0.05)$ as shown in Table 3 .

\section{Gene Expression}

FADS2 mRNA gene expression showed a highly significant increased expression in our breastfed groups of babies by 109 folds increase vs. 5 folds for the artificially formula fed, Fig. 1 and the attached amplification plot and gene expression bars, Fig. 2 and 3.

Table 1. Mean \pm SD of weight $(\mathrm{Kg})$ of subjects over the period of $(0-12 \mathrm{Ws})$ among the studied groups

\begin{tabular}{|c|c|c|c|c|c|}
\hline \multirow[b]{2}{*}{$\begin{array}{l}\text { Groups } \\
\text { Weight }(\mathrm{Kg})\end{array}$} & \multicolumn{2}{|c|}{ Group (PET-BF) } & \multicolumn{3}{|c|}{ Group 11 (PET-AF) } \\
\hline & Mean \pm SD & Ratelweek & Mean \pm SD & Ratelweek & p-value \\
\hline At Birth & $2.16 \pm 0.22$ & & $2.09 \pm 0.24$ & & $>0.05$ \\
\hline 2 Weeks & $2.64 \pm 0.22$ & $240 \mathrm{gm} / \mathrm{w}$ & $2.27 \pm 0.19$ & $185 \mathrm{gm} / \mathrm{w}$ & 0.001 \\
\hline 4 Weeks & $3.27 \pm 0.25$ & $315 \mathrm{gm} / \mathrm{w}$ & $2.59 \pm 0.29$ & $160 \mathrm{gm} / \mathrm{w}$ & 0.001 \\
\hline 6 Weeks & $3.9 \pm 0.31$ & $157 \mathrm{gm} / \mathrm{w}$ & $3.38 \pm 0.29$ & $197 \mathrm{gm} / \mathrm{w}$ & 0.001 \\
\hline 8 Weeks & $4.55 \pm 0.22$ & $162 \mathrm{gm} / \mathrm{w}$ & $4.04 \pm 0.41$ & $165 \mathrm{gm} / \mathrm{w}$ & 0.001 \\
\hline 12 weeks & $5.15 \pm 0.21$ & $150 \mathrm{gm} / \mathrm{w}$ & $4.95 \pm 0.44$ & $171 \mathrm{gm} / \mathrm{w}$ & $>0.05$ \\
\hline
\end{tabular}

Table 2. Mean $\pm \mathrm{SD}$ of head Circumference $(\mathrm{Cm})$ and length $(\mathrm{Cm})$ of subjects after the period of $(12 \mathrm{Ws})$ among the studied groups

\begin{tabular}{llll}
\hline & Mean \pm SD & & \\
Groups & - & & \\
parameter & Group I (PET-BF) & Group II (PET-AF) & \\
\hline Head circum. $(\mathrm{Cm})$. & $\mathrm{N}=15$ & $\mathrm{~N}=15$ & $\mathrm{p}$ \\
Length $(\mathrm{Cm})$. & $33.0 \pm 1$ & $33.27 \pm 0.7$ & $>0.05$ \\
\hline
\end{tabular}

Table 3. Comparison between breastfed and the artificially-fed groups as regards laboratory parameters at 3 months of age

\begin{tabular}{llll}
\hline & Mean \pm SD & & \\
& - & & \\
& Breastfed $(\mathrm{N}=15)$ & Artificially fed $(\mathrm{N}=15)$ & $\mathrm{p}$ \\
\hline $\mathrm{RBC}\left(\times 10^{6}\right)$ & $4.5167 \pm 0.32$ & $4.3767 \pm 0.22$ & $>0.05$ \\
MCV $(\mathrm{fl})$ & $79.4667 \pm 2.58$ & $78.4167 \pm 2.66$ & $>0.05$ \\
MCH $(\mathrm{pg})$ & $24.85 \pm 1.1$ & $24.8167 \pm 1.15$ & $>0.05$ \\
$\mathrm{Hb}(\mathrm{g} / \mathrm{dl})$ & $12.2767 \pm 0.40$ & $12.05 \pm 0.40$ & $>0.05$ \\
WBC $\left(\times 10^{3}\right)$ & $7.69 \pm 2.43$ & $7.125 \pm 1.72$ & $>0.05$ \\
Platelets $\left(\times 10^{3}\right)$ & $272.75 \pm 57.95$ & $277.85 \pm 49.05$ & $>0.05$ \\
\hline
\end{tabular}

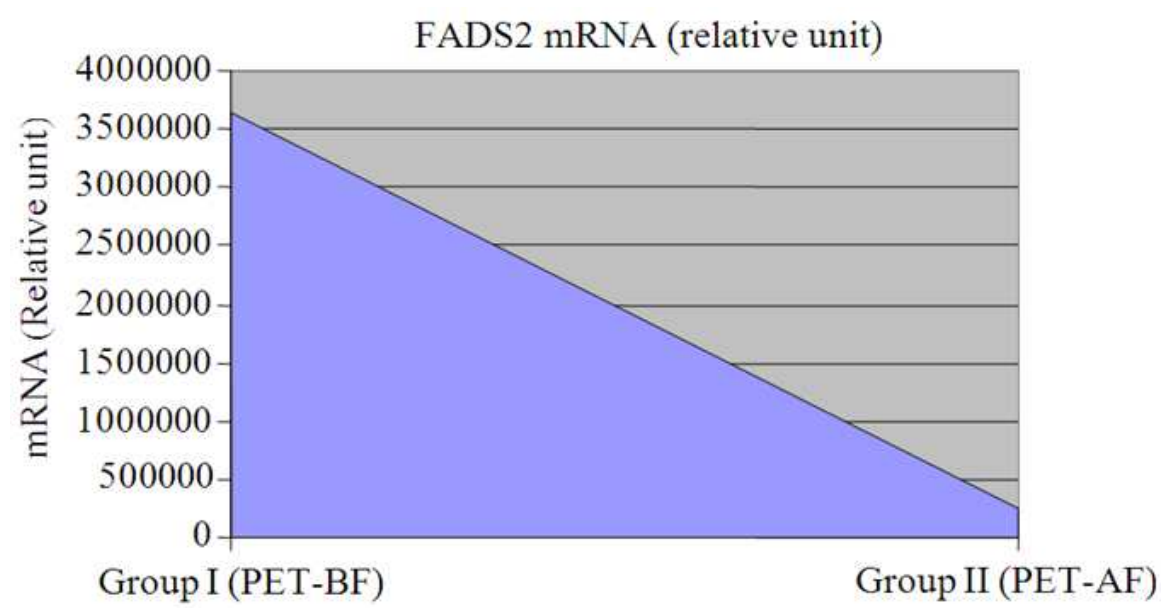

Fig.1. FADS2 mRNA expression by relative unit in both groups 


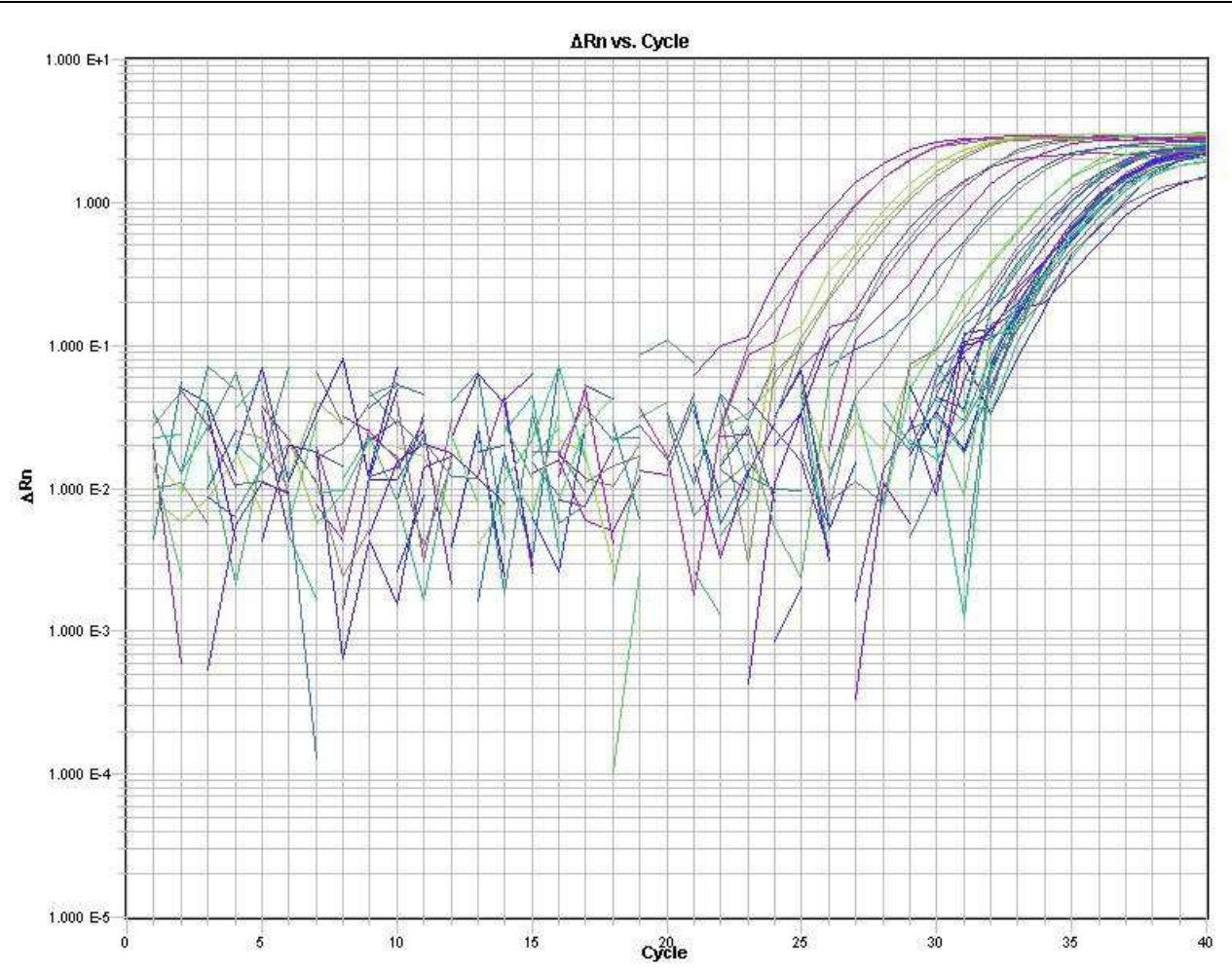

Fig. 2. Indicates post-run amplification plot (ABI 7900 Fast real time machine) of group I and group II for FADS2 mRNA as selected target detector and GAPDH mRNA as housekeeping detector

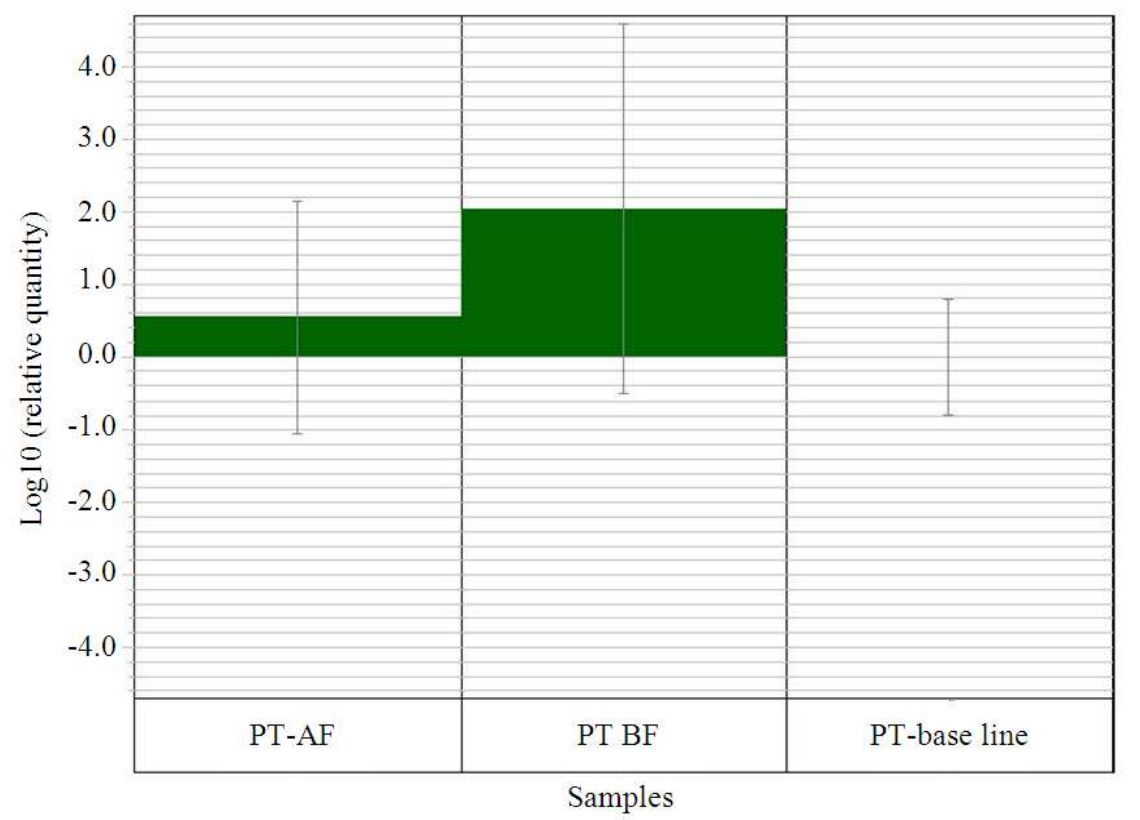

PT: Preterm AF: Artificially fed --BF: Breast fed-Base line: Preterm at birth

Fig. 3. Gene expression bars (ABI 7900) of the studied groups Gene expression levels of FADS2 mRNA for both two groups samples are indicated by green bars (Fig. 3). This color also indicates the samples in RQ. Because group II samples are used as calibrators, the expression levels are set to one. But because the expression levels were blotted as $\log 10$ values (and the $\log 10$ of 1 is 0 ), the expression level of the group II samples appears as zero in the graph. Fold expression changes are calculated using 2- $\triangle \Delta C \mathrm{CT}$. The FADS2 mRNA expression levels were 109 folds higher in infants who were exclusively breastfed in the first 12 weeks versus those who fed artificial milk 


\section{Discussion}

Molecular Biology of intelligence has linked DNA sequence with behavioral differences such as intelligence. Nutrition can affect the brain throughout the life cycle, with profound implications for mental health and degenerative disease. Many aspects of nutrition, from entire diets to specific nutrients, affect brain structure and function. Cognition refers to the mental processes involved in acquiring knowledge and the integration of these processes into responses such as learning, attention, memory, intelligence (Intelligence Quotient; IQ) and consciousness (Dauncey, 2009).

Proteins also undergo modifications and interactions that cannot be predicted from genomics alone. Functional genomics operates under three major categories: Gene manipulation, gene expression, profiling and proteomics. Gene expression can be determined by the presence of mRNA, which could be transcribed into proteins.

The pattern of growth among our groups was different between groups, especially gain in weight. Although weight differences at 3 months were similar, the genetic differentiation was completely different. This indicates that the growth and development in early infancy cannot be assessed by macro measurements as weight or length gain, but must involve more accurate and specific tests to ensure that the nutrients fed to the child meet its needs for optimal development (Zelkowitz et al., 2008).

In our study the breast milk fed group had significantly higher increment rates in weight gain in the first 8 weeks and formula fed group did not show catch up except after 8 weeks of age. The difference in weight was collapsed between breastfed and formula fed infants to become non-statistically significant at 3 months $(5.15 \pm 0.21)(4.95 \pm 0.44)$ respectively $\mathrm{p}>0.05$.

The increase of genetic expression FADS2 noted in this study over the first 3 months, in the exclusively breastfed group of babies that was not seen in non breastfed fed indicates that the mammary gland is affected by practices related to early feeding which in turn influence gene expression. Xie and Innis (2008) showed that FADS1 and FADS2 influenced the fatty acids of pregnant women and suggested that genetic variation among women may influence maternal-toinfant transfer of fatty acids during pregnancy and in lactation will via breast milk, influence fatty acids nutrition of the breast fed infant. This suggested that FADS2 genes may be primed during pregnancy through the mammary gland. This function probably continues during lactation and influences the genes in the newborn. Hence the mother supplies these fatty acids for growing fetus, but after birth these FA are supplied through the mammary gland. Hence when the newborn is several from this important regulatory organ, it is also deprived of the source that regulates gene expression. In this case the baby's suckling at the breast is what probably controls the feedback mechanism (Morales et al., 2011).

The effect of breastfeeding on brain development has been examined in many studies, especially two aspects of brain development, cognitive development and the development of visual acuity (Michaelsen et al., 1994; Akter and Rahman, 2010). There are a number of studies, which indicate that the feeding mode during early childhood has a long-term effect on cognitive development (Jedrychowski et al., 2012). Moreover, Lucas et al. (1992) found that infant who had been fed breast milk through a nasogastric tube in life had higher Intelligence Quotient (IQ) at 7 to 8 year of age compared to formula fed one and that was confirmed and cited by Isaacs et al. (2010).

Many studies have explained the higher IQ shown in breast fed as linked to high content of long chain polyunsaturated fatty acids LC- PUFA; linolic acid, $\alpha$ linoliec acid; arachidonic acid and decosahexaenoic acid in human milk. These fatty acids are the major fatty acids and are of major importance for the development of the brain and nervous system (Cohen et al., 2005; Lo et al., 2012). The significant role played by the mammary gland on the gene function is shown by the absence any such an effect on the group of babies who were not suckling at the breast. Also although the artificially fed group in our study received milk formula supplemented with polyunsaturated free fatty acids yet this didn't influence their gene expression or function. Other researchers found no differences in development between the breast-fed and artificially fed groups fed supplemented with LC-PUFA but studies were done over a short period (Steer et al., 2010).

Moreover it indicates that the Mammary Gland (MG) plays an important role not only in nourishing the baby but also in regulating their genetic information. Rodriguez-Cruz et al. (2011) showed that the expression of desaturases in MG was significantly higher (12.3- fold for FADS1 and 41.2 fold for FADS2) during the late pregnancy and throughout lactation 31.7 fold higher for FADS1 and 67.1 fold higher for FADS2) than in non pregnant rats. Accordingly, a higher content of LC-PUF as was found in lactating MG than in non-pregnant rats. Results suggest that MG participate from late pregnancy and throughout lactation by expressing desaturases and elongases as a mechanism involved in LC-PUFAs synthesis (Glaser et al., 2010).

Children who are breastfed were shown to have superior neurodevelopment outcomes and the duration of breastfeeding also affect a child's intelligence (Park, 2005). The effect on the IQ of babies who continue to breastfeed for longer duration cannot be explained by the mere presence for the long chain fatty acids per say, but are related to the extent of genetic expression. The term metabolic imprinting describes the process whereby cells have a biological memory for nutritional 
influence that can be passed on to daughter cells through mitotic cell division (Rodriguez-Cruz et al., 2011). This could be the mechanism were by the MG exerts its effect on FADS2 expression in the neonate and thus potentiating their ability to produce PUFA throughout their life even after weaning.

Studies have shown that IQ differences between the early exclusively breastfed, particularly the preterm ones, remain and continue to increase with age (Kramer et al., 2008). This indicates the potentiated effect induced by the process of enhancement of gene expression on later brain development. This could explain the significantly higher response in FADS2 expression in our group of breastfed babies. Epigenetic refers to stable alterations in gene expression that arise during development and cell proliferation and are subsequently retained through mitosis (Jaenisch and Bird, 2003). The interaction between genes and environment may be different between emotional intelligence an IQ tests. This probably indicates the importance of external stimuli for development of genes. Hence it's important to keep mothers with babies together, especially in early period of life by implementing regimes such as continuous skin to skin care or Kangaroo mother care as these regimes enhance mother infant interactions and have been shown to have significant positive effects on child development. While such epigenetic changes in the genome are heritable but do not involve mutation of the DNA itself, DNA methylation is accepted as one of the most important underlying biological mechanisms regulating the metabolic imprinting process (Jaenisch and Bird, 2003). DNA methylation is the post replication process by which cytosine nucleotides in $\mathrm{CpG}$ sequences are methylated to 5-methylcytosine, forming gene-specific methylation patterns (Park, 2005). DNA methylation might be responsible for the stable maintenance of the particular gene expression pattern through mitotic cell division (Santos et al., 2005). Nutrition research has emphasized the role of diet in DNA methylation and effects on stable epigenetic changes. Restricted feeding during early phases of development causes metabolic imprinting that leads to increased susceptibility to cardiovascular disease in late life, increase insulin sensitivity as an adaptive response or decrease longevity. The hormonal milieu present during pregnancy results in lasting changes in the pattern in gene expression in the mammary gland, leading to permanent changes in cell fate that determine the subsequent proliferative response of the gland. These hormonally induced persistent changes in gene expression may be mediated by epigenetic alterations in DNA methylation status of promoter sequences (Park, 2005).

The pattern of growth among our groups was different, with a significant higher growth rate in and weight gain, in addition increases in blood indices in the exclusively breastfed at 3 month of age. This indicates that the growth and development in early infancy are interlinked and are affected by mother infant interaction, infant feeding practices and the effects of genetic imprinting, genetic expression in a bidirectional manner, in which each enhances the other in a continuous cycle of feedback for meeting the needs for optimal early and later development (Forcada-Guex et al., 2006; Martin et al., 2011). Another study by Keim et al. (2012) have shown that depressive symptoms in mothers were inversely associated with concentrations of PUFA in breast milk. This supports the role of mammary gland in influencing PUFA levels and thereby enhancing genetic expression as early in pregnancy. Hence enhancing mother infant interactions can reverse postpartum depression by improving PUFA levels, which in turn enhances gene expression controlling these fatty acids (Glaser et al., 2011). Depression symptoms were significantly lowered in mothers who were encouraged to do more skin to skin care (Kymre and Bondas 2013). Hence the mother benefits from the enhanced genetic expression probably by interlink between FADS2 expression, PUFA and postpartum depression (Saleh et al., 2013).

\section{Conclusion}

Tissue availability of Polyunsaturated Fatty Acids (PUFAs) is strongly linked to the extent of genetic expression entailed by mammary gland during lactation. Dietary intake and metabolic turnover of these fatty acids have a major impact of human development and health. The higher FADS2 expression observed in the breast fed group may be used to predict higher IQ scores in the breast-fed preterm.

The most significant associations and the highest proportion of genetically variability imply the need for more extensive studies with large samples number to show the significance and outcome of such findings. However, our study demonstrates clear evidence of importance of early exclusive breastfeeding in the early period of critical development of the preterm for both the baby and the mother.

\section{Acknowledgment}

Research was performed with use of the equipment and instruments of Molecular Biology and Biotechnology Unit Faculty of Medicine Benha University.

We would like to express our appreciation to Talkha Central Hospital, Egyptian Ministry of Health for assistance in collecting the clinical samples and data.

\section{Funding Information}

This study was done by self-financing 


\section{Author's Contributions}

A.M.A. Abul-Fadl: Conception and design, analysis and interpretation of data, drafting the article.

A.I. Ali: Design, supervision the molecular biology technique, revising the article.

N.F. Alhusseini: Molecular biology technique, analysis and interpretation of data, contributed unpublished essential data, writing the manuscript and corresponding author for publication.

S.M. El-Taher: Statistical analysis, interpretation of results, revising the article.

A.A. Abuzied: Collecting samples and clinical data, collecting the scientific materials, writing the article.

\section{Ethics}

We confirm that this manuscript has not been published elsewhere and is not under consideration by another journal. Each author confirms the manuscript represents honest work. All authors have approved the manuscript. Each author agrees with the order in which his name appears on the title page. Study design and methods were approved by Ethics Committee of Benha Faculty of Medicine.

\section{References}

Akter, S. and M.M. Rahman, 2010. Duration of breastfeeding and its correlates in Bangladesh. J. Health Popul. Nut., 28: 595-601. PMID: 21261205

Caspi, A., B. Williams, J. Kim-Cohen, I.W. Craig and B.J. Milne et al., 2007. Moderation of breastfeeding effects on the IQ by genetic variation in fatty acid metabolism. Proc. Nat. Acad. Sci. USA, 104: 18860-18865. DOI: 10.1073/pnas.0704292104

Cohen, J.T., D.C Bellinger, W.E. Connor and B.A. Shaywitz, 2005. A quantitative analysis of prenatal intake of n-3 polyunsaturated fatty acids and cognitive development. Am. J. Preventive Med., 29: 366-374. PMID: 16242603

Dauncey, M.J., 2009. New insights into nutrition and cognitive neuroscience. Proc. Nut. Soc., 68: 408415. DOI: $10.1017 / \mathrm{S} 0029665109990188$

Forcada-Guex, M., B. Pierrehumbert, A. Borghini, A. Moessinger and C. Muller-Nix, 2006. Early dyadic patterns of mother-infant interactions and outcomes of prematurity at 18 months. Pediatrics, 118: e107114. PMID: 16818525

Glaser, C., E. Lattka, P. Rzehak, C. Steer and B. Koletzko, 2011. Genetic variation in polyunsaturated fatty acid metabolism and its potential relevance for human development and health. Matern. Child. Nut., 7: 27-40.

DOI: $10.1111 / j .1740-8709.2011 .00319 . x$
Glaser, C., J. Heinrich and B. Koletzko, 2010. Role of FADS1 and FADS2 polymorphisms in polyunsaturated fatty acid metabolism. Metabolism, 59: 993-999.

DOI: 10.1016/J.METABOL.2009.10.022

Isaacs, E.B., B.R. Fischl, B.T. Quinn, W.K. Chong and D.G. Gadian et al., 2010. Impact of breast milk on intelligence quotient, brain size and white matter development. Pediatr Res., 67: 357-362. DOI: 10.1203/PDR.0b013e3181d026da

Jaenisch, R. and A. Bird, 2003. Epigenetic regulation of gene expression: How the genome integrates intrinsic and environmental signals. Nat. Genet., 33: 245-254. PMID: 12610534

Jedrychowski, W., F. Perera, J. Jankowski, M. Butscher and E. Mroz et al., 2012. Effect of exclusive breastfeeding on the development of children's cognitive function in the Krakow prospective birth cohort study. Eur. J. Pediatr., 171: 151-158. DOI: $10.1007 / \mathrm{s} 00431-011-1507-5$

Keim, S.A., J.L. Daniels, A.M. Siega-Riz, N. Dole and A.H. Herring et al., 2012. Depressive symptoms during pregnancy and the concentration of fatty acids in breast milk. J. Hum. Lact., 28: 189-195. DOI: $10.1177 / 0890334411424727$

Kramer, M.S., F. Aboud, E. Mironova, I. Vanilovich and R.W. Platt et al., 2008. Breastfeeding and child cognitive development: New evidence from a large randomized trial. Arch. Gen. Psychiatry, 65: 578584. DOI: $10.1001 /$ archpsyc.65.5.578

Kymre, I.G. and T. Bondas, 2013. Skin-to-skin care for dying preterm newborns and their parents--a phenomenological study from the perspective of NICU nurses. Car. Sci., 27: 669-76. DOI: $10.1111 / j .1471-6712.2012 .01076 . x$

Livak, K.J. and T.D. Schmittgen, 2001. Analysis of relative gene expression data using real-time quantitative PCR and the 2(-Delta Delta $\mathrm{C}(\mathrm{T})$ ) Method. Methods, 25: 402-8. PMID: 11846609

Lo, A., J. Sienna, E. Mamak, N. Djokanovic and C. Westall et al., 2012. The effects of maternal supplementation of polyunsaturated Fatty acids on visual, neurobehavioural and developmental outcomes of the child: A systematic review of the randomized trials. Obstetr. Gynecol. Int., 2012: 591531-591539. DOI: $10.1155 / 2012 / 591531$

Lucas, A., R. Morley, T.J. Cole, G. Lister and C. Leeson-Payne, 1992. Breast milk and subsequent intelligence quotient in children born preterm. Lancet, 339: 261-264. DOI: 10.1016/0140-6736(92)91329-7

Martin, M., L. Clare, A.M. Altgassen, M.H. Cameron and F. Zehnder, 2011. Cognition-based interventions for healthy older people and people with mild cognitive impairment. Cochrane Database Syst. Rev. DOI: 10.1002/14651858.CD006220.pub2 
Michaelsen, K.F., P.S. Larsen, B.L. Thomsen and G. Samuelson, 1994. The Copenhagen cohort study on infant nutrition and growth: Duration of breastfeeding and influencing factor. Acta Paediatr., 83: 565-571. PMID: 7919750

Morales, E., M. Bustamante, J.R. Gonzalez, M. Guxens and M. Torrent et al., 2011. Genetic variants of the FADS gene cluster and ELOVL gene family, colostrums LC-PUFA levels, breastfeeding and child cognition. PLoS ONE, 6: e17181-e17181. DOI: 10.1371/journal.pone.0017181

Mortensen, E.L., K.F. Michaelsen, S.A. Sanders and J.M. Reinisch, 2002. The association between duration of breastfeeding and adult intelligence. JAMA, 287: 2365-2371. PMID: 11988057.

Park, C.S., 2005. Role of compensatory mammary growth in epigenetic control of gene expression. Faseb. J., 19: 1586-1591. PMID: 16195367

Rodriguez-Cruz, M., R. SUnchez, A.M. SUnchez, S.L. Kelleher and F. SUnchez-Muóz et al., 2011. Participation of mammary gland in long-chain polyunsaturated fatty acid synthesis during pregnancy and lactation in rats. Biochim. Biophys. Acta, 1811: 284-93. DOI: $10.1016 /$ j.bbalip.2011.01.007.

Saleh, E.S., W. El-Bahei, M.A. El-Hadidy and A. Zayed, 2013. Predictors of postpartum depression in a sample of Egyptian women. Neuro Psychiatr. Dis. Treat., 9: 15-24. DOI: 10.2147/NDT.S37156

Santos, K.F., T.N. Mazzola and H.F. Carvalho, 2005. The prima donna of epigenetics: The regulation of gene expression by DNA methylation. Braz. J. Med. Biol. Res., 38: 1531-1541.

DOI: $10.1590 / \mathrm{S} 0100-879 X 2005001000010$
Steer, C.D., G. Davey Smith, P.M. Emmett, J.R. Hibbeln and J. Golding, 2010. FADS2 Polymorphisms modify the effect of breastfeeding on child IQ. PLoS ONE, 5: e11570-e11570.

DOI: 10.1371 journal.pone. 0011570

Walfisch, A., C. Sermer, A. Cressman and G. Koren, 2013. Breast milk and cognitive development--the role of confounders: A systematic review. BMJ Open., 23: e003259-e003259.

DOI: 10.1136/bmjopen-2013-003259

Wilfinger, W.W., K. Mackey and P. Chomczynskip, 1997. Effect of $\mathrm{pH}$ and ionic strength on the spectrophotometric assessment of nucleic acidpurity. Biotechniques, 22: 474-476. PMID: 9067025

Xie, L. and S.M. Innis, 2008. Genetic variants of the FADS1 FADS2 gene cluster are associated with altered (n-6) and (n-3) essential fatty acids in plasma and erythrocyte phospholipids in women during pregnancy and in breast milk during lactation. J. Nut., 138: 2222-2228.

DOI: $10.3945 /$ jn. 108.096156

Zelkowitz, P., N. Feeley, I. Shrier, R. Stremler and R Westreich et al., 2008. The cues and care trial: A randomized controlled trial of an intervention to reduce maternal anxiety and improve developmental outcomes in very low birth weight infants. BMC Pediatr., 8: 38-38. DOI: $10.1186 / 1471-2431-8-38$

Butte, N., M. Lopez-Alarcon and C. Garza, 2002. Nutrient Adequacy of Exclusive Breastfeeding for the Term Infant During the First Six Months of Life. 1st Edn., World Health Organization. Geneva, ISBN-10: 9241562110. 